\title{
VEGF inhibitors in EGFR-mutated lung cancer: a never-ending story?
}

\author{
Mariam Alexander, Balazs Halmos \\ Department of Oncology, Albert Einstein College of Medicine/Montefiore Medical Center, Bronx, NY, USA \\ Correspondence to: Balazs Halmos, MD. Department of Oncology, Albert Einstein College of Medicine/Montefiore Medical Center, Bronx, NY, USA. \\ Email: bahalmos@montefiore.org. \\ Comment on: West HL, Moon J, Wozniak AJ, et al. Paired Phase II Studies of Erlotinib/Bevacizumab for Advanced Bronchioloalveolar Carcinoma or \\ Never Smokers With Advanced Non-Small-cell Lung Cancer: SWOG S0635 and S0636 Trials. Clin Lung Cancer 2018;19:84-92.
}

Submitted Oct 26, 2018. Accepted for publication Nov 06, 2018.

doi: $10.21037 / \mathrm{atm} .2018 .11 .20$

View this article at: http://dx.doi.org/10.21037/atm.2018.11.20

Over the last 15 years, multiple generations of EGFR tyrosine kinase inhibitors (TKIs) have completely transformed the landscape of management of EGFRmutated lung cancers but are rarely used in other settings. In the pre-molecular testing era, the $1^{\text {st }}$ generation reversible EGFR inhibitor, erlotinib, was shown to prolong survival in patients with stage IIIB/IV non-small cell lung cancer (NSCLC) after failure of first- or second-line chemotherapy compared to placebo [overall survival (OS) was 6.7 vs. 4.7 months, hazard ratio (HR) $0.70, \mathrm{P}<0.001]$ (1). This led to FDA approval and broad usage as a result, up until withdrawal of this indication (2). Bevacizumab, a humanized monoclonal antibody targeting vascular endothelial growth factor (VEGF) inhibits angiogenesis and regresses pre-existing tumor blood vessels (3). It also improves drug delivery by decreasing interstitial fluid pressure (4). When administered in combination with platinum-based chemotherapy in patients with advanced NSCLC, a significant survival benefit (OS 12.3 vs. 10.3 months in favor of the group receiving bevacizumab, HR 0.79; $\mathrm{P}=0.003$ ) was noted in the ECOG4599 study leading to FDA approval and common use of this agent (5). As bevacizumab and erlotinib target these key tumor pathways in complementary mechanisms and there is little overlap in their toxicities, it was a reasonable hypothesis that combining the two agents would improve outcomes compared to each agent alone. In 2005, Herbst et al. undertook a phase I/II study to evaluate the efficacy of combining erlotinib and bevacizumab in patients with advanced NSCLC who had progressed on at least one line of chemotherapy (6). The median OS was a promising
12.6 months [1-year survival $54.2 \%$ with progressionfree survival (PFS) of 6.2 months] with the most common adverse effects being rash, diarrhea and proteinuria. The non-molecularly selected ATLAS trial assessed the efficacy of combining erlotinib and bevacizumab in patients with recurrent or refractory NSCLC after failure of combination chemotherapy (7). Even though there was no improvement in OS (HR 0.92, $\mathrm{P}=0.5341$ ), the median PFS was significantly, albeit modestly, prolonged to 4.8 months with the combination compared to 3.7 months with bevacizumab alone (HR 0.71, $\mathrm{P}<0.001$ ). These results were confirmed in the similarly designed phase $3 \mathrm{BeT}$ trial where there was no improvement in OS (9.3 months in the combined group compared to 9.2 months in control groups) (8). In this study, subgroup analysis of patients with EGFR-mutated tumors did not show a statistically significant improvement in overall survival $(\mathrm{P}=0.1826)$. The lack of OS benefit might have been partly related to the lack of power in this subset for an OS benefit as well as confounding effect of active subsequent therapies.

Although these results were promising, it was unclear at the time which patients would benefit from an EGFR TKI before molecular testing became widely available providing the backdrop and context to the concurrently conducted SWOG studies focusing on a combination of erlotinib/bevacizumab in two distinct patient subsets (9). The first study, S0635 focused on patients with advanced bronchioloalveolar carcinoma (BAC), recently renamed to adenocarcinoma-in-situ, which is a unique entity where the entire tumor grows along alveolar septae (lepidic growth pattern) and lacks features of invasion (10). On 
radiographic imaging, it can appear as ground glass opacities in a single mass/nodular form versus presenting in a consolidative or multinodular form and these tumors are often fluorodeoxyglucose (FDG) negative on PET/CT. A retrospective analysis showed that BAC was an independent predictor of response to the $1^{\text {st }}$ generation EGFR TKI, gefitinib $(\mathrm{P}<0.001)(11)$. Moreover, EGFR mutations are frequently present in BACs (12) justifying using this lung cancer subtype as the "enrichment" factor in this trial. The second study enrolled never smokers with advanced lung cancer as these patients, which make up about $10 \%$ of the overall advanced NSCLC population were shown to have a longer survival benefit with erlotinib compared to smokers (1) and non-smoking status was similarly found to be an independent predictor of response to $1^{\text {st }}$ generation EGFR TKIs (11). Based on these results and scientific considerations that were relevant at the time, the phase II trials SWOG S0635 and S0636 were designed to investigate if there was a meaningful survival extension of the combination of erlotinib/bevacizumab in advanced lung cancer specifically in patients with BAC or never smokers (9).

These twin trials enrolled patients with BAC/AdenoBAC (S0635) or never smokers (S0636) with stage IIIB/IV lung adenocarcinoma, who had no previous biologic therapy with an EGFR or angiogenesis inhibitor or have received chemotherapy in the 4 weeks before enrollment. The targeted median OS below which the regimen would not be of interest was 12 months, which led to a target population of 80 patients in each trial providing a power of 0.86 to rule out the null hypothesis. The cutoff for which the regimen would warrant testing in the phase III setting was an improved OS $>16$ months. 84 patients in the S0635 trial and 85 patients in the S0636 trial received erlotinib with bevacizumab until progression or toxicity. The study included patients with brain metastases and progression of disease was measured using CT scans after every 2 cycles and then with increased intervals after 6 months without evidence of progression.

In the S0635 trial, the median cycles delivered was 7, with a median follow up of 37.6 months. Median PFS was 5 months (95\% CI: 4-7 months) and median OS was 21 months (95\% CI: 14-26 months) with a survival rate of $67 \%$ at 1 year. For the S0636 trial with a median of 10.5 cycles delivered, the median follow-up was 41.5 months. Median PFS was 7.4 months (95\% CI: 6.1-10.9 months) and median OS was 29.8 months (95\% CI: $22.5-37.8$ months) with a survival rate of $78 \%$ at 1 year. The main grade $3 / 4$ toxicities were rash (13\%), diarrhea (10\%) and fatigue (9\%). Post hoc analysis showed a correlation of better OS in patients who had developed diarrhea. Unfortunately, in the S0635 trial only $32 / 85$ patients had tissue available for EGFR molecular marker testing and meaningful conclusions could not be drawn as to correlations with biomarkers, such as EGFR mutation status. In the S0636 trial, 42 patients had enough tissue for FISH/mutation analysis. There was a significantly higher response rate in EGFR-mutant tumors (89\% vs. 33\% in EGFR wild type, $\mathrm{P}=0.01$ ) but this was not associated with PFS or OS.

All in all, these studies met their primary endpoint demonstrating a promising OS in both studies with the combination. Given the lack of a comparator group and the generally significantly better OS of the two subsets of patients, it is still hard to reach very firm conclusions from either study and from the optic of recognizing the advances made since, the study results lack significant impact. However, these studies represented a tremendous effort on the part of the authors demonstrating the ability to conduct and complete studies on small lung cancer patient subsets and were based on the relevant knowledge during the time of study design. Of course, since the trial was initiated the field has moved to molecular detection of EGFR mutations for EGFR TKI therapy selection and the understanding of other key oncogenic alterations enriched in non-smokers, for example ALK/ROS alterations as well as key subsets of BACs, such as K-Ras mutations and NRG1-fusions present in mucinous types with specific targeted treatment considerations.

Since the initial OPTIMAL and EURTAC trials using $1^{\text {st }}$ generation EGFR TKIs erlotinib and gefitinib, the field has rapidly progressed (13-15). The second generation irreversible TKIs, which provide a broader inhibition of the ERBB family, afatinib and dacomitinib have shown unique benefits in tumors with exon 19 deletion and certain uncommon EGFR mutations (16) and now also a survival benefit over gefitinib in the case of dacomitinib $(17,18)$. The third generation TKI, osimertinib, which has unique activity in T790M mutated NSCLC showed superiority over chemotherapy in the acquired resistance setting as seen in the AURA3 and over $1^{\text {st }}$ generation EGFR TKIs in the FLAURA study $(19,20)$. However, given the broad range of resistance mechanisms that now are emerging on osimertinib, there is a strong need to re-consider combination strategies using alternative options such as immuno-oncology agents, MET inhibitors, MEK1/2 inhibitors or angiogenesis inhibitors re-igniting the interest in the results of studies such as S0635 and S0636 and it is quite 
Table 1 Selected studies combining EGFR and VEGF inhibitors in lung cancer patients

\begin{tabular}{|c|c|c|c|c|c|c|}
\hline Study/investigator & Phase & $\begin{array}{l}\text { Drug combination/ } \\
\text { comparison }\end{array}$ & $\mathrm{N}$ & $\begin{array}{l}\text { Line of therapy/EGFR } \\
\text { mutation-based } \\
\text { selection (yes/no) }\end{array}$ & $\begin{array}{l}\text { Primary } \\
\text { EP }\end{array}$ & Clinical outcomes \\
\hline $\begin{array}{l}\text { BeTA/Herbst et al., } \\
2011 \text { (8) }\end{array}$ & III & $\mathrm{B}+\mathrm{E}$ vs. $\mathrm{E}$ & 636 & $2^{\text {nd }}$ line/no & OS & $\begin{array}{c}\text { OS: } 9.3 \mathrm{~m} \text { in } \mathrm{B}+\mathrm{E} \text { vs. } 9.2 \mathrm{~m} \text { in } \mathrm{E} \text { alone } \\
\text { (HR 0.97, } 95 \% \mathrm{Cl}: 0.80-1.18 \\
\mathrm{P}=0.7583) \text {; PFS: } 3.4 \mathrm{~m} \text { in } \mathrm{B}+\mathrm{E} \text { vs. } 1.7 \mathrm{~m} \\
\text { in } \mathrm{E} \text { (HR } 0.62,95 \% \mathrm{Cl}: 0.52-0.75)\end{array}$ \\
\hline $\begin{array}{l}\text { NTR528/Dingemans } \\
\text { et al., } 2011 \text { (22) }\end{array}$ & II & B vs. E & 47 & $1^{\text {st }}$ line $/$ no* $^{*}$ & NPR & $\begin{array}{c}\text { NPR: } 75 \% \text {; mPFS: } 3.8 \text { m (95\% Cl: } \\
\text { 2.3-5.4); mOS: } 6.9 \text { m (95\% Cl: 5.5-8.4) }\end{array}$ \\
\hline $\begin{array}{l}\text { SAKK19/Zappa } \\
\text { et al., } 2012 \text { (23) }\end{array}$ & II & $\begin{array}{l}\mathrm{B}+\mathrm{E} \rightarrow \mathrm{C} \text { at } \\
\text { progression }\end{array}$ & 103 & $2^{\text {nd }}$ line/no & DSR & DSR: 54.5\%; mTTP: $4.1 \mathrm{~m}$; OS: $14.1 \mathrm{~m}$ \\
\hline $\begin{array}{l}\text { ATLAS/Johnson } \\
\text { et al., } 2013 \text { (7) }\end{array}$ & III & $\begin{array}{l}(\mathrm{C}+\mathrm{B}) \times 4 \text { cycles } \rightarrow \\
\quad \mathrm{B} \text { vs. } \mathrm{B}+\mathrm{E}\end{array}$ & 746 & $2^{\text {nd }}$ line/no & PFS & $\begin{array}{c}\text { PFS: } 3.7 \mathrm{~m} \text { in } \mathrm{B} \text { vs. } 4.8 \mathrm{~m} \text { in } \mathrm{B}+\mathrm{E} \\
\text { (HR 0.71, } \mathrm{P}<0.001) ; \mathrm{OS}: 13.3 \text { vs. } 14.4 \mathrm{~m} \\
\text { (HR 0.92; } \mathrm{P}=0.5341)\end{array}$ \\
\hline $\begin{array}{l}\text { JO25567/Seto } \\
\text { et al., } 2014 \text { (25); } \\
\text { Yamamoto et al., } \\
2018(26)\end{array}$ & II & $\mathrm{B}+\mathrm{E}$ vs. $\mathrm{E}$ & 154 & $1^{\text {st }}$ line/yes & PFS & $\begin{array}{c}\text { PFS: } 16.0 \mathrm{~m} \text { in } \mathrm{B}+\mathrm{E} \text { vs. } 9.7 \mathrm{~m} \text { in } \mathrm{E}(\mathrm{HR} \\
0.54, \mathrm{P}=0.0015) ; \mathrm{OS}: 47.0 \text { vs. } 47.4 \mathrm{~m} \\
\text { (HR 0.81, } \mathrm{P}=0.3257)\end{array}$ \\
\hline $\begin{array}{l}\text { LUN04-77/Riggs } \\
\text { et al., } 2013 \text { (27) }\end{array}$ & II & $\begin{array}{c}\mathrm{B}+\mathrm{E} \\
(\mathrm{PS} \geq 2 \text { or age } \geq 70)\end{array}$ & 25 & $1^{\text {st }}$ line/no & rNPD & rNPD was $28 \%$ \\
\hline $\begin{array}{l}\text { ABC/Hata et al., } \\
2018 \text { (31) }\end{array}$ & II & $\mathrm{B}+\mathrm{A}$ & 32 & Any/yes & PFS & $\begin{array}{c}\text { PFS: } 6.3 \text { m (95\% Cl: 3.9-9.7); ORR: } \\
\text { 18.8\% (95\% Cl: 7.2-36.4\%) }\end{array}$ \\
\hline $\begin{array}{l}\text { JVDL } \\
\text { (NCT02789345)/Yu } \\
\text { et al., } 2017 \text { (32) }\end{array}$ & $\mathrm{lb}$ & $\mathrm{O}+\mathrm{R}$ vs. $\mathrm{O}+\mathrm{N}$ & 25 & $\begin{array}{l}2^{\text {nd }} \text { line or after } \\
\text { TKI/yes (T790M) }\end{array}$ & Safety & Ongoing \\
\hline $\begin{array}{l}\text { OLCSG1404/ } \\
\text { Harada et al., } \\
2017 \text { (33) }\end{array}$ & $\mathrm{lb}$ & $A+B$ & 6 & $2^{\text {nd }}$ line/yes & Safety & Ongoing \\
\hline $\begin{array}{l}\text { RELAY/Reck et al., } \\
2018 \text { (34) }\end{array}$ & $\mathrm{lb}$ & $E+R$ & 14 & $1^{\text {st }}$ line/yes & Safety & PFS: 17.1 m (95\% Cl: 8.8 m-NR) \\
\hline $\begin{array}{l}\text { BEVERLY/Gridelli } \\
\text { et al., } 2016 \text { (35) }\end{array}$ & III & $\mathrm{B}+\mathrm{E}$ vs. $\mathrm{E}$ & 200 & $1^{\text {st }}$ line/yes & PFS & Ongoing \\
\hline
\end{tabular}

Table 1 (continued) 
Table 1 (continued)

\begin{tabular}{|c|c|c|c|c|c|c|}
\hline Study/investigator & Phase & $\begin{array}{l}\text { Drug combination/ } \\
\text { comparison }\end{array}$ & $\mathrm{N}$ & $\begin{array}{c}\text { Line of therapy/EGFR } \\
\text { mutation-based } \\
\text { selection (yes/no) }\end{array}$ & $\begin{array}{l}\text { Primary } \\
\text { EP }\end{array}$ & Clinical outcomes \\
\hline
\end{tabular}

*, EGFR mutation status assessed after treatment. m, months; w, weeks; E, erlotinib; B, bevacizumab; C, chemotherapy; A, afatinib; O, osimertinib; R, ramucirumab; N, necitumumab; P, panitumumab; PFS, median progression-free survival; ORR, objective response rate, OS, overall survival; NPR, non-progression rate at 6 weeks; DSR, disease stabilization rate; rNPD, rate of non-progressive disease at 4 months.

possible that addition of these agents to a front-line TKI could potentially delay resistance mechanisms (Table 1) (39).

Indeed, in studies where patients were molecularly selected specifically for EGFR mutations, there was a notable improvement in PFS with the combination of EGFR TKI/bevacizumab. For instance, the phase 2 JO25567 study assessed the efficacy of combining erlotinib with bevacizumab as first-line therapy in patients with advanced NSCLC with an activating EGFR mutation (25). Promisingly, the median PFS was very significantly prolonged to 16.0 months with the combination compared to 9.7 months with erlotinib alone (HR 0.54, 95\% CI: 0.36-0.79, P=0.0015). However, at the ASCO 2018 meeting, after longer follow-up, no notable OS benefit was reported in the combination regimen [OS $47.0 \mathrm{vs}$. 47.4 months (HR 0.81, $\mathrm{P}=0.3257$ )] (26). The single arm, phase 2 BELIEF trial corroborated these findings with overall PFS of 13.2 months (95\% CI: 10.3-15.5 months) in patients with EGFR activating mutation receiving both erlotinib and bevacizumab (29). Interestingly, there was a further benefit in patients who later were noted to harbor a T790M resistance mutations achieving a PFS of 16.0 months [95\% CI: 12.7 months-not reached (NR)]. These data suggest that the combination of erlotinib and bevacizumab is beneficial at least in terms of achieving more durable remissions and delaying resistance in the first-line setting in patients with activating EGFR mutations.

Most recently, the phase III NEJ026 trial assigned patients with advanced NSCLC with activating EGFR mutations, who were treatment naive to erlotinib/ bevacizumab versus erlotinib alone (36). There was again significant improvement in PFS in the combined group compared to erlotinib alone (16.9 vs. 13.3 months, HR $0.61, \mathrm{P}=0.016$ ) and OS results will be eagerly awaited. The most common toxicities were hypertension, proteinuria and hemorrhage and as in prior studies, the combination appeared generally well tolerated. Although the above listed trials show an impressive improvement in PFS with the combination of EGFR TKI with VEGF inhibitors, it has not translated into an overall survival benefit as of yet possibly related to extended survival of these patients and effective subsequent therapies confounding the results. However, the standard of care for first-line management of advanced EGFR-mutated NSCLC in the US is now the third generation osimertinib, which makes the control arm in these trials also obsolete. A phase $1 / 2$ study combining osimertinib with bevacizumab is ongoing, with preliminary results showing that the combination was tolerable and effective in the first-line setting with potential follow-up studies being planned (38). The combination of osimertinib and the VEGFR2 inhibiting monoclonal antibody, ramucirumab is also being investigated in a phase Ib study, with preliminary results showing median PFS not reached (90\% CI: 5.49-NR) and PFS at 6 months of $64 \%$ (90\% CI: 43.7-78.6\%) (40).

There is currently a rapid paradigm shift towards combining immune checkpoint inhibitors with chemotherapy in patients with advanced NSCLC. Based on the positive results of the Keynote-021 and 189 studies, the immune checkpoint inhibitor, pembrolizumab is approved for front line treatment of metastatic non-squamous NSCLC in combination with chemotherapy irrespective 
of PD-L1 expression $(41,42)$. Tumor survival requires vascularisation, which is usually abnormal in architecture. VEGF inhibitors can lead to the normalization of this vasculature leading to increased $\mathrm{T}$-cell infiltration, possibly enhancing an immune response against the tumor (43). Therefore, combining immune check point inhibitors with VEGF inhibitors may help enhance immunotherapy efficacy and decrease modes of resistance. While the listed Keynote studies excluded EGFR-mutated patients as prior data suggested lack of activity of checkpoint inhibitors in these oncogene-driven, low mutation burden tumors, the phase III, IMpower150 trial combining the PD-L1 inhibitor atezolizumab with bevacizumab and platinum doublet chemotherapy did permit the enrolment of patients with EGFR/ALK positive tumors and demonstrates unique promise for this concept (44). The median PFS for the entire group was improved by 1.5 months with the fourdrug regimen compared to the control arm of carboplatin/ Taxol/bevacizumab (8.3 vs. 6.98 months, $\mathrm{P}<0.001)$ with an associated significant improvement in OS (19.2 vs. 14.7 months, $\mathrm{P}=0.0164)$. The data was furthermore quite striking in the subset of patients with EGFR and ALK mutations (PFS 9.7 months for the 4 drugs vs. 6.1 months in those with bevacizumab and chemotherapy alone). Interestingly, the PFS curves separate more over time following completion of the chemotherapy suggesting that there may be an ongoing synergy between bevacizumab and atezolizumab providing now hope for a variety of chemo/immunotherapy/anti-angiogenic combinations as an effective strategy for EGFR-mutated tumors. While this study does not allow the separation of benefit driven by bevacizumab but certainly continues to provide fodder for a continued role into studies of VEGF-directed therapy.

All in all, more than 10 years following the publication of the pivotal ECOG4599 study, we continue to see intriguing signals of benefit of VEGF-directed therapy in multiple settings, such as combination with front-line and secondline chemotherapy, in synergy with chemo/immunotherapy as well as EGFR TKI therapy. While studies such as the S0635/0636 studies might not have yielded conclusive answers, they provided further data to support ongoing investigations of this subject as well as demonstration that collaborative efforts can permit completion of important studies on small patient subsets and thereby West et al., should be commended for their significant contributions to the body of literature on the utility of anti-angiogenic therapy in advanced NSCLC and we need to hope that over the next few years we will be able to reach final conclusions to this never-ending story.

\section{Acknowledgements}

None.

\section{Footnote}

Conflicts of Interest: B Halmos has received research funding from Merck, Astra-Zeneca, Boehringer-Ingelheim, Pfizer, Novartis, GSK, AbbVie, Mirati, Eli-Lilly, Takeda and BMS and consulting fees from Foundation Medicine, Guardant Health 360, Eli-Lilly, Novartis, Pfizer, BoehringerIngelheim, Astra-Zeneca, Spectrum, BMS, Merck, Genentech and Takeda. M Alexander has no conflicts of interest to declare.

\section{References}

1. Shepherd FA, Rodrigues Pereira J, Ciuleanu T, et al. Erlotinib in previously treated non-small-cell lung cancer. N Engl J Med 2005;353:123-32.

2. Cicènas $\mathrm{S}$, Geater SL, Petrov $\mathrm{P}$, et al. Maintenance erlotinib versus erlotinib at disease progression in patients with advanced non-small-cell lung cancer who have not progressed following platinum-based chemotherapy (IUNO study). Lung Cancer 2016;102:30-7.

3. O'Connor JP, Carano RA, Clamp AR, et al. Quantifying antivascular effects of monoclonal antibodies to vascular endothelial growth factor: insights from imaging. Clin Cancer Res 2009;15:6674-82.

4. Yanagisawa M, Yorozu K, Kurasawa M, et al. Bevacizumab improves the delivery and efficacy of paclitaxel. Anticancer Drugs 2010;21:687-94.

5. Sandler A, Gray R, Perry MC, et al. Paclitaxel-carboplatin alone or with bevacizumab for non-small-cell lung cancer. N Engl J Med 2006;355:2542-50.

6. Herbst RS, Johnson DH, Mininberg E, et al. Phase I/II trial evaluating the anti-vascular endothelial growth factor monoclonal antibody bevacizumab in combination with the HER-1/epidermal growth factor receptor tyrosine kinase inhibitor erlotinib for patients with recurrent nonsmall-cell lung cancer. J Clin Oncol 2005;23:2544-55.

7. Johnson BE, Kabbinavar F, Fehrenbacher L, et al. ATLAS: randomized, double-blind, placebo-controlled, phase IIIB trial comparing bevacizumab therapy with or without erlotinib, after completion of chemotherapy, with bevacizumab for first-line treatment of advanced non- 
small-cell lung cancer. J Clin Oncol 2013;31:3926-34.

8. Herbst RS, Ansari R, Bustin F, et al. Efficacy of bevacizumab plus erlotinib versus erlotinib alone in advanced non-small-cell lung cancer after failure of standard first-line chemotherapy (BeTa): a doubleblind, placebo-controlled, phase 3 trial. Lancet 2011;377:1846-54.

9. West HL, Moon J, Wozniak AJ, et al. Paired Phase II Studies of Erlotinib/Bevacizumab for Advanced Bronchioloalveolar Carcinoma or Never Smokers With Advanced Non-Small-cell Lung Cancer: SWOG S0635 and S0636 Trials. Clin Lung Cancer 2018;19:84-92.

10. Borczuk AC. Prognostic considerations of the new World Health Organization classification of lung adenocarcinoma. Eur Respir Rev 2016;25:364-71.

11. Miller VA, Kris MG, Shah N, et al. Bronchioloalveolar pathologic subtype and smoking history predict sensitivity to gefitinib in advanced non-small-cell lung cancer. J Clin Oncol 2004;22:1103-9.

12. Matsumoto S, Iwakawa R, Kohno T, et al. Frequent EGFR mutations in noninvasive bronchioloalveolar carcinoma. Int J Cancer 2006;118:2498-504.

13. Zhou $\mathrm{C}, \mathrm{Wu} \mathrm{YL}$, Chen $\mathrm{G}$, et al. Erlotinib versus chemotherapy as first-line treatment for patients with advanced EGFR mutation-positive non-small-cell lung cancer (OPTIMAL, CTONG-0802): a multicentre, open-label, randomised, phase 3 study. Lancet Oncol 2011;12:735-42.

14. Rosell R, Carcereny E, Gervais R, et al. Erlotinib versus standard chemotherapy as first-line treatment for European patients with advanced EGFR mutation-positive non-small-cell lung cancer (EURTAC): a multicentre, open-label, randomised phase 3 trial. Lancet Oncol 2012;13:239-46.

15. Novello S, Barlesi F, Califano R, et al. Metastatic nonsmall-cell lung cancer: ESMO Clinical Practice Guidelines for diagnosis, treatment and follow-up. Ann Oncol 2016;27:v1-27.

16. Yang JC, Sequist LV, Geater SL, et al. Clinical activity of afatinib in patients with advanced non-small-cell lung cancer harbouring uncommon EGFR mutations: a combined post-hoc analysis of LUX-Lung 2, LUX-Lung 3, and LUX-Lung 6. Lancet Oncol 2015;16:830-8.

17. Yang JC, Wu YL, Schuler M, et al. Afatinib versus cisplatin-based chemotherapy for EGFR mutation-positive lung adenocarcinoma (LUX-Lung 3 and LUX-Lung 6): analysis of overall survival data from two randomised, phase 3 trials. Lancet Oncol 2015;16:141-51.
18. Mok TS, Cheng Y, Zhou X, et al. Improvement in Overall Survival in a Randomized Study That Compared Dacomitinib With Gefitinib in Patients With Advanced Non-Small-Cell Lung Cancer and EGFR-Activating Mutations. J Clin Oncol 2018;36:2244-50.

19. Mok TS, Wu YL, Ahn MJ, et al. Osimertinib or PlatinumPemetrexed in EGFR T790M-Positive Lung Cancer. N Engl J Med 2017;376:629-40.

20. Soria JC, Ohe Y, Vansteenkiste J, et al. Osimertinib in Untreated EGFR-Mutated Advanced Non-Small-Cell Lung Cancer. N Engl J Med 2018;378:113-25.

21. Herbst RS, O'Neill VJ, Fehrenbacher L, et al. Phase II study of efficacy and safety of bevacizumab in combination with chemotherapy or erlotinib compared with chemotherapy alone for treatment of recurrent or refractory non small-cell lung cancer. J Clin Oncol 2007;25:4743-50.

22. Dingemans AM, de Langen AJ, van den Boogaart $\mathrm{V}$, et al. First-line erlotinib and bevacizumab in patients with locally advanced and/or metastatic non-small-cell lung cancer: a phase II study including molecular imaging. Ann Oncol 2011;22:559-66.

23. Zappa F, Droege C, Betticher D, et al. Bevacizumab and erlotinib (BE) first-line therapy in advanced non-squamous non-small-cell lung cancer (NSCLC) (stage IIIB/IV) followed by platinum-based chemotherapy (CT) at disease progression: a multicenter phase II trial (SAKK 19/05). Lung Cancer 2012;78:239-44.

24. Ciuleanu T, Tsai CM, Tsao CJ, et al. A phase II study of erlotinib in combination with bevacizumab versus chemotherapy plus bevacizumab in the first-line treatment of advanced non-squamous non-small cell lung cancer. Lung Cancer 2013;82:276-81.

25. Seto T, Kato T, Nishio M, et al. Erlotinib alone or with bevacizumab as first-line therapy in patients with advanced non-squamous non-small-cell lung cancer harbouring EGFR mutations (JO25567): an open-label, randomised, multicentre, phase 2 study. Lancet Oncol 2014;15:1236-44.

26. Yamamoto N, Seto T, Nishio M, et al. Erlotinib plus bevacizumab (EB) versus erlotinib alone (E) as first-line treatment for advanced EGFR mutation-positive nonsquamous non-small-cell lung cancer (NSCLC): Survival follow-up results of JO25567. J Clin Oncol 2018;36:9007.

27. Riggs H, Jalal SI, Baghdadi TA, et al. Erlotinib and bevacizumab in newly diagnosed performance status 2 or elderly patients with nonsquamous non-small-cell lung cancer, a phase II study of the Hoosier Oncology Group: 
LUN04-77. Clin Lung Cancer 2013;14:224-9.

28. Thomas M, Fischer J, Andreas S, et al. Erlotinib and bevacizumab versus cisplatin, gemcitabine and bevacizumab in unselected nonsquamous nonsmall cell lung cancer. Eur Respir J 2015;46:219-29.

29. Rosell R, Dafni U, Felip E, et al. Erlotinib and bevacizumab in patients with advanced non-small-cell lung cancer and activating EGFR mutations (BELIEF): an international, multicentre, single-arm, phase 2 trial. Lancet Respir Med 2017;5:435-44.

30. Wang Y, Wang H, Jiang Y, Zhang Y, Wang X. A randomized phase III study of combining erlotinib with bevacizumab and panitumumab versus erlotinib alone as second-line therapy for Chinese patients with non-smallcell lung cancer. Biomed Pharmacother 2017;89:875-9.

31. Hata A, Katakami N, Kaji R, et al. Afatinib Plus Bevacizumab Combination After Acquired Resistance to EGFR Tyrosine Kinase Inhibitors in EGFR-Mutant NonSmall Cell Lung Cancer: Multicenter, Single-Arm, Phase 2 Trial (ABC Study). Cancer 2018. [Epub ahead of print].

32. Yu H, Planchard D, Yang JC, et al. P1.04-001 Osimertinib with Ramucirumab or Necitumumab in Advanced T790Mpositive EGFR-Mutant NSCLC: Preliminary Ph1 Study Results. J Thorac Oncol 2017;12:S1972.

33. Harada D, Nogami N, Kozuki T, et al. 426P A phase I trial of afatinib (Afa) and bevacizumab (Bev) in chemo-naïve patients (pts) with advanced non-small-cell lung cancer (NSCLC) harboring EGFR-mutations: OLCSG1404. Ann Oncol 2017;28:mdx671.015.

34. Reck M, Garon EB, Paz-Ares L, et al. Randomized, Double-Blind Phase Ib/III Study of Erlotinib With Ramucirumab or Placebo in Previously Untreated EGFR-Mutant Metastatic Non-Small-Cell Lung Cancer (RELAY): Phase Ib Results. Clin Lung Cancer 2018;19:213-220.e4.

35. Gridelli C, Rossi A, Ciardiello F, et al. BEVERLY: Rationale and Design of a Randomized Open-Label Phase III Trial Comparing Bevacizumab Plus Erlotinib Versus

Cite this article as: Alexander M, Halmos B. VEGF inhibitors in EGFR-mutated lung cancer: a never-ending story? Ann Transl Med 2018;6(23):446. doi: 10.21037/atm.2018.11.20
Erlotinib Alone as First-Line Treatment of Patients With EGFR-Mutated Advanced Nonsquamous Non-Small-Cell Lung Cancer. Clin Lung Cancer 2016;17:461-5.

36. Furuya N, Fukuhara T, Saito H, et al. Phase III study comparing bevacizumab plus erlotinib to erlotinib in patients with untreated NSCLC harboring activating EGFR mutations: NEJ026. J Clin Oncol 2018;36:9006.

37. Maemondo M, Fukuhara T, Sugawara S, et al. NEJ026: Phase III study comparing bevacizumab plus erlotinib to erlotinib in patients with untreated NSCLC harboring activating EGFR mutations. Ann Oncol 2016;27:1286TiP.

38. Yu HA, Hayes SA, Young RJ, et al. A phase 1 study of osimertinib and bevacizumab as initial treatment for patients with EGFR-mutant lung cancers. J Clin Oncol 2017;35:9033.

39. Yu HA, Arcila ME, Rekhtman N, et al. Analysis of tumor specimens at the time of acquired resistance to EGFR-TKI therapy in 155 patients with EGFR-mutant lung cancers. Clin Cancer Res 2013;19:2240-7.

40. Planchard D, Yu HA, Yang JC, et al. Efficacy and safety results of ramucirumab in combination with osimertinib in advanced T790M-positive EGFR-mutant NSCLC. J Clin Oncol 2018;36:9053.

41. Gandhi L, Rodriguez-Abreu D, Gadgeel S, et al. Pembrolizumab plus Chemotherapy in Metastatic Non-Small-Cell Lung Cancer. N Engl J Med 2018;378:2078-92.

42. Langer CJ, Gadgeel SM, Borghaei H, et al. Carboplatin and pemetrexed with or without pembrolizumab for advanced, non-squamous non-small-cell lung cancer: a randomised, phase 2 cohort of the open-label KEYNOTE-021 study. Lancet Oncol 2016;17:1497-508.

43. Oelkrug C, Ramage JM. Enhancement of T cell recruitment and infiltration into tumours. Clin Exp Immunol 2014;178:1-8.

44. Socinski MA, Jotte RM, Cappuzzo F, et al. Atezolizumab for First-Line Treatment of Metastatic Nonsquamous NSCLC. N Engl J Med 2018;378:2288-301. 